\title{
The Influence of Genetic Syndromes on the Algorithm of Cleft Lip and Palate Repair - A Retrospective Study
}

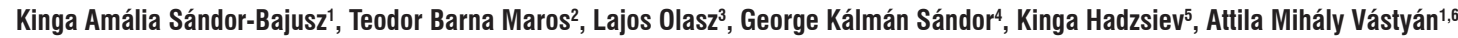 \\ Departments of ${ }^{1}$ Paediatrics, ${ }^{3}$ Dentistry, Oral and Maxillofacial Surgery and ${ }^{5}$ Medical Genetics, University of Pécs, Pécs, ${ }^{2}$ Department of Otorhinolaryngology, Ferenc \\ Flór County Hospital, Kistarcsa, ${ }^{6}$ Paediatric Surgery, Department of Paediatrics, University of Pécs, Pécs, Hungary, ${ }^{4}$ Department of Oral and Maxillofacial Surgery, \\ Medical Research Centre, University of Oulu, Oulu University Hospital, Oulu, Finland
}

\section{Abstract}

Introduction: This study aimed to determine if the treatment algorithm used for nonsyndromic cleft patients required alteration to manage syndromic cleft lip and/or palate patients. Methods: The records of patients managed by the Pécs Cleft Team between January 1999 and December 2015 were analyzed retrospectively. The sources of the data included clinical and genetic records. Results: A total of 607 patients were managed by the cleft team during the study. Sixteen patients $(2.6 \%)$ were noted to be afflicted with a particular identifiable syndrome. Seven different genetic syndromes and one sequence were present in the study. The Pierre Robin sequence occurred most often, comprising 50\% of the cohort. The treatment algorithm used in managing nonsyndromic clefts required modification in 13 of the 16 syndromic patients. Discussion: The presence of a genetic syndrome may notably affect the treatment algorithm in children born with cleft lip and/or palate. The surgical treatment of certain associated anomalies has by necessity, priority over the timing of the reconstruction of the cleft lip and/or cleft palate in syndromic patients.

Keywords: Child, cleft lip, cleft palate, syndrome, treatment timing

\section{INTRODUCTION}

Cleft lip and/or cleft palate (CLP) are common developmental anomalies. ${ }^{[1]}$ In general, the worldwide incidence of clefts is estimated to be between 1 and 2.21 cases per 1000 live births. ${ }^{[1]}$ In most cases, CLP occurs as an isolated anomaly. However, the association of CLP with genetic syndromes, the so-called syndromic cleft lip and palate (SCLP), has been described previously in the seventies. ${ }^{[2]}$ At that time, only 154 cleft-related syndromes were known in contrast to the well over 500 syndromes recognized in the literature today. ${ }^{[3]}$ SCLP patients represent between $10 \%$ and $30 \%$ of CLP cases, according to past and current publications. ${ }^{[3-5]}$

The aim of this clinical study was to identify syndromic cleft patients and evaluate how their genetic syndrome influenced the timing of the algorithm in the treatment of CLP. The study was conducted on patients managed by the Pécs Cleft Team (PCT) between January 1999 and December 2015.

\begin{tabular}{|l|l|}
\hline \multicolumn{3}{|c|}{ Access this article online } \\
\hline Quick Response Code: & Website: \\
\hline & www.amsjournal.com \\
\hline & \\
\hline
\end{tabular}

\section{Methods}

A study of nonsyndromic and syndromic cleft patients managed and followed by the PCT was conducted over the 16 years between January 1999 and December 2015. Detailed clinical documentation of all patients, including genetic and epidemiological data, was required for inclusion in the study. The data were collected retrospectively without personal identifying details. At the time of the data collection, permission from the regional ethical committee was not deemed to be obligatory because of the retrospective nature of the study. Special permission was obtained and granted for data collection from the Hungarian Congenital Abnormality Registry (HCAR). The

Address for correspondence: Dr. Kinga Amália Sándor-Bajusz, School of Clinical Neurosciences, University of Pécs, Pécs, Hungary. E-mail: sandor.kinga@pte.hu
Received: $27-03-2021$

Accepted: 31-08-2021
Last Revised: $08-04-2021$

Published: 29-11-2021
This is an open access journal, and articles are distributed under the terms of the Creative Commons Attribution-NonCommercial-ShareAlike 4.0 License, which allows others to remix, tweak, and build upon the work non-commercially, as long as appropriate credit is given and the new creations are licensed under the identical terms.

For reprints contact: WKHLRPMedknow_reprints@wolterskluwer.com

How to cite this article: Sándor-Bajusz KA, Maros TB, Olasz L, Sándor GK, Hadzsiev K, Vástyán AM. The influence of genetic syndromes on the algorithm of cleft lip and palate repair - A retrospective study. Ann Maxillofac Surg 2021;11:270-3. 
Ethics Committee of the University of Pécs waived the need for ethics approval and the need to obtain consent for the collection, analysis and publication of the retrospectively obtained and anonymized data for this study. The reason for this waiver was the retrospective nature of this study and the anonymized nature of the data used in the study. All procedures performed in the study were conducted in accordance with the ethics standards given in the 1964 Declaration of Helsinki, as revised in 2013.

Special emphasis was placed on the syndromic features of the patients and their associated anomalies. The type and timing of the surgeries or interventions unrelated to the clefts were listed and categorized. The timing of the cleft lip and/or cleft palate repair was recorded as well, and was compared with the algorithm used for nonsyndromic cleft patients. The Online Mendelian Inheritance in Man database ${ }^{[6]}$ was used to identify the genetic syndromes. Epidemiological data were obtained from the HCAR. The study used descriptive statistics consisting of means and percentages of the presenting syndromes and participants of the study, which were calculated and used along with standard deviations in the data analysis.

\section{RESULTS}

Among the 607 CLP patients, 25 children (4.1\%) had associated anomalies noted during the study period. Sixteen $(2.6 \%)$ of

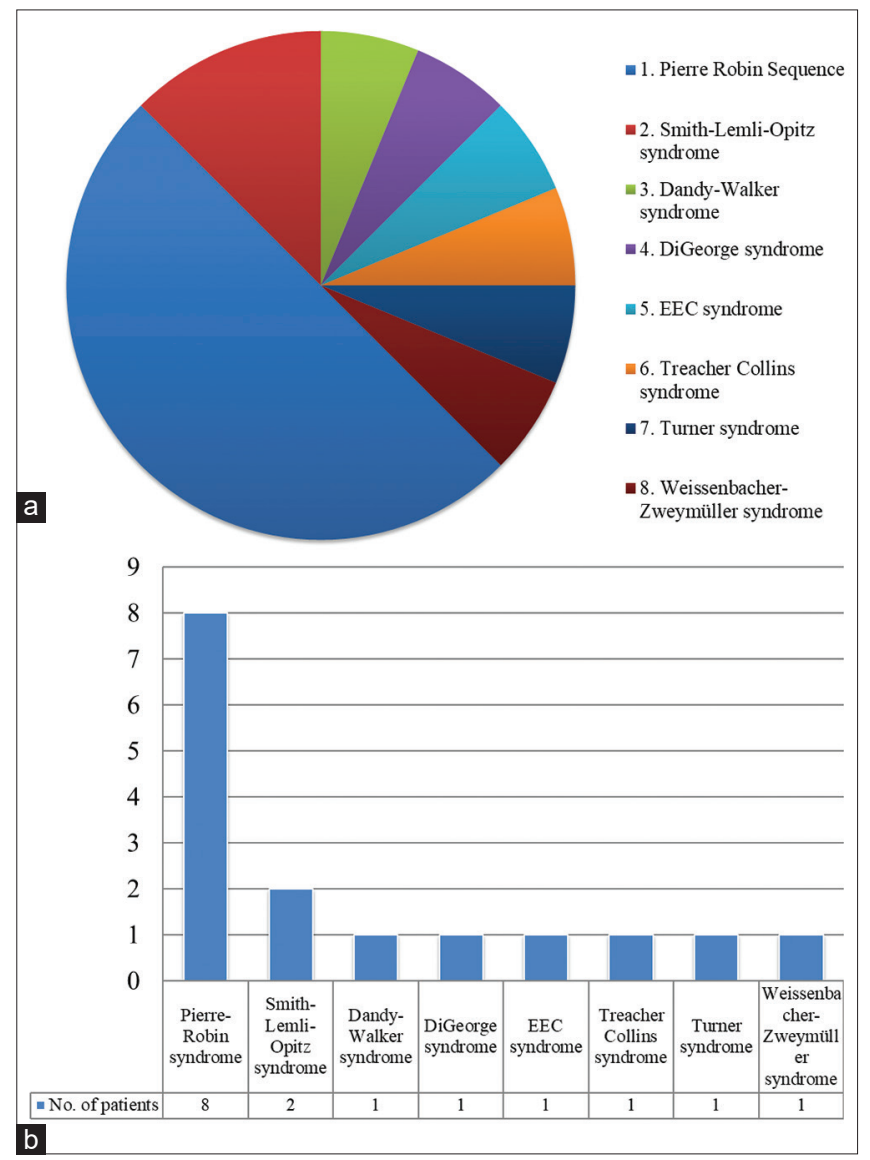

Figure 1: (a) The distribution of the seven genetic syndromes and one sequence present in the cohort. (b) Number of individuals in each group the 607 CLP patients were found to be SCLP cases. A total of seven different genetic syndromes and one sequence were identified in this cohort [Figure 1a and $\mathrm{b}$ ].

Pierre Robin sequence (PRS) comprised $50 \%$ of all cases. Ten patients $(60 \%)$ were boys and six $(40 \%)$ were girls of the SCLP group. The majority of the SCLP patients had cleft palate only, $n=13(81 \%)$ [Figure 2]. The other syndromes observed in the cohort included: Smith-Lemli Opitz syndrome, Dandy-Walker syndrome, DiGeorge syndrome, Ectrodactyly-ectodermal dysplasia-clefting syndrome, Treacher Collins syndrome, Turner syndrome, and Weissenbacher-Zweymüller syndrome.

The algorithm used by the PCT had to be modified for most of the SCLP patients $(n=13,81 \%)$. The modifications were necessary due to the nature and needs of the given syndrome. This was true in all SCLP cases, except for one patient. The timing of the cleft repair procedure in the SCLP cohort is illustrated in Figure 3.

The authors observed notable delays in the timing of the palate repair in SCLP patients. In two SCLP patients, the palatoplasty procedure was completed much later, at 4 years of age. In addition, 15 patients underwent additional surgeries due to the presence of the syndromes and associated medical conditions [Figure 4]. These operations had of necessity priority over the repair of the CLP deformities. Tracheostomies were needed in three patients with PRS.

Secondary operations for CLP were required in six patients $(37.5 \%)$. Speech improvement operations or pharyngoplasty and tympanostomy tube placements were the most common secondary operations. These procedures were mainly required in patients with PRS [Figure 5].

\section{DISCUSSION}

Treating SCLP patients is by nature, more complex than treating nonsyndromic cleft patients. Syndromic patients require more attention and support for their multiple potential special needs from both the family and the health care facility, including the cleft teams..$^{[1,7-11]}$

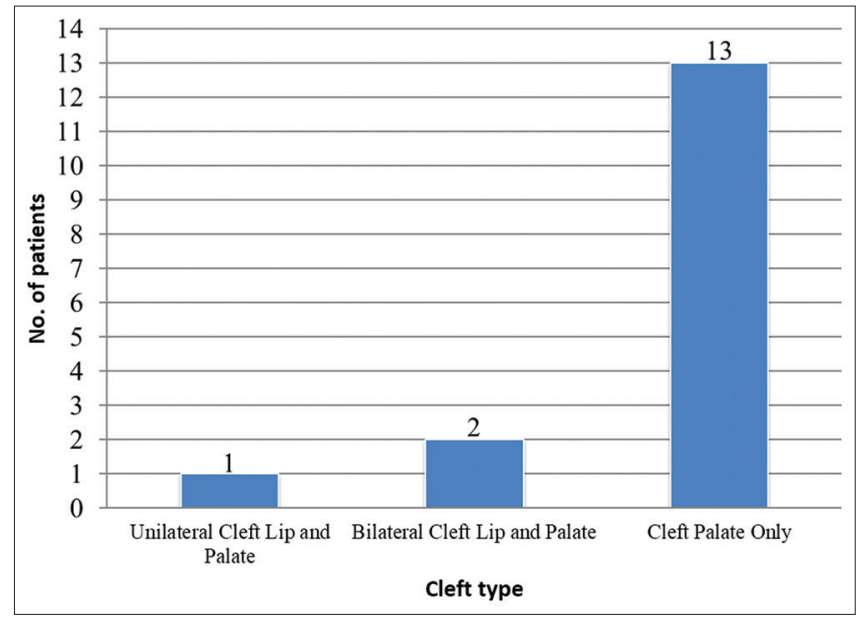

Figure 2: The distribution of cleft type in syndromic patients 


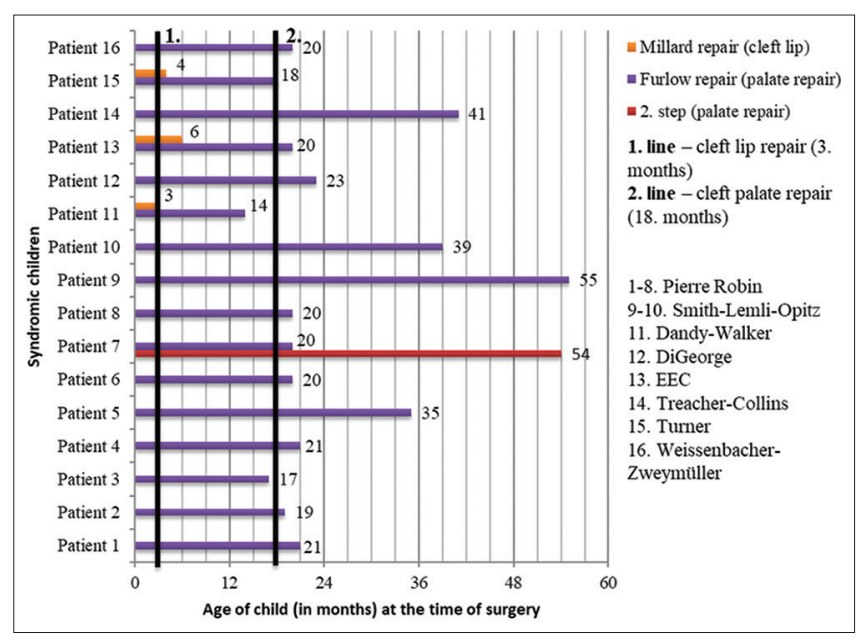

Figure 3: The timing of the cleft repair surgery for syndromic patients. Vertical lines in bold (1 and 2) represent the usual timing of the cleft repair surgeries carried out by the Pécs Cleft Team. Patients 1-16 are grouped according to the types of syndromes

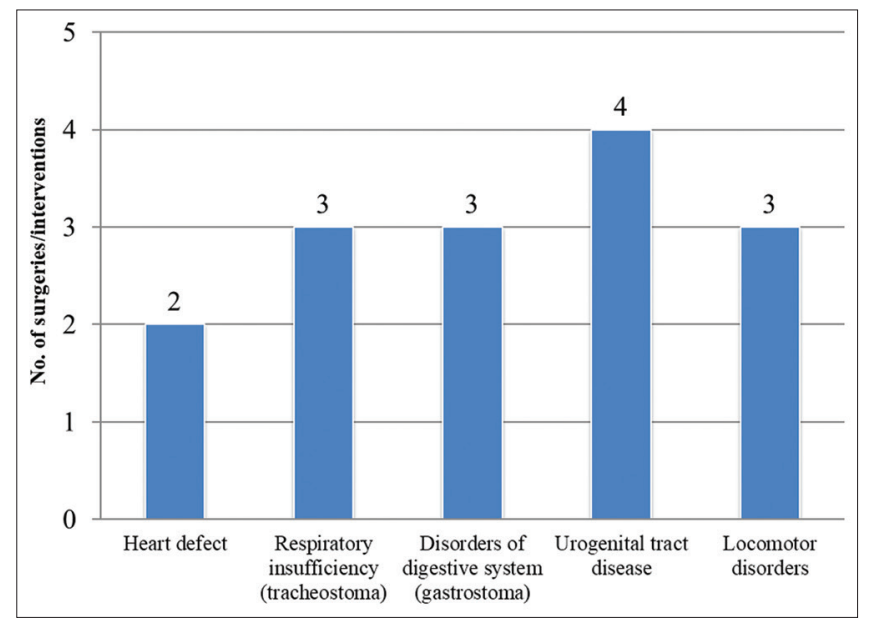

Figure 4: The distribution of additional surgeries for the affected organ system (s) for syndromic patients

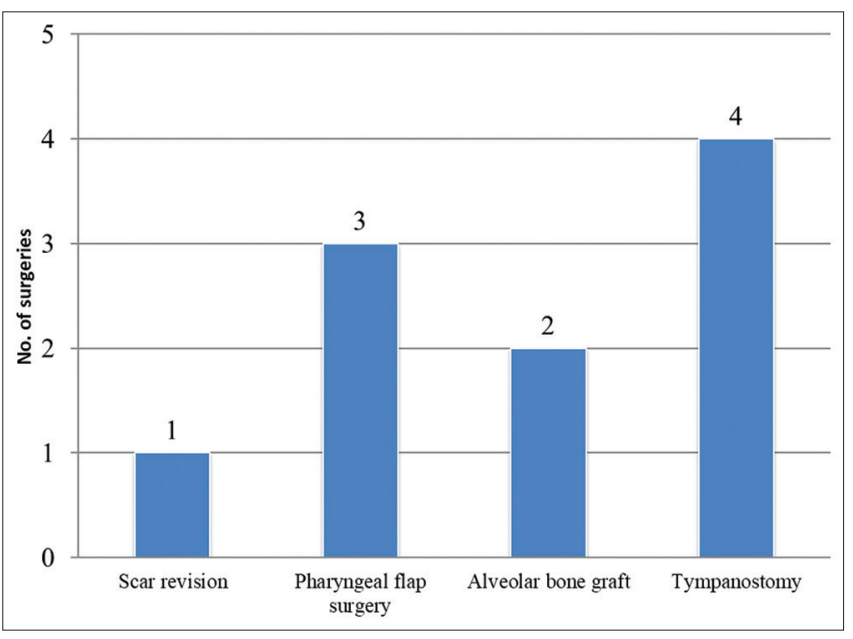

Figure 5: Types of secondary ancillary operations carried out on syndromic cleft patients
The percentage of the SCLP patients managed by the PCT was $2.6 \%$ during the study. This number is below the $10 \%$ and $30 \%$ prevalence described in the literature. ${ }^{[3-5,12,13]}$ On the other hand, the prevalence of PRS in the SCLP cohort was similar to the literature, according to the data obtained from the HCAR. In contrast, Smith-Lemli-Opitz, Dandy-Walker syndrome, and Turner syndrome were underrepresented in this SCLP cohort. The under-diagnosis and/or reporting of cases could be responsible for their low prevalence.

Interestingly, two very rare syndromes both Ectrodactylyectodermal dysplasia-clefting syndrome and WeissenbacherZweymüller syndrome were present in the syndromic cohort. ${ }^{[14-16]}$ A center for rare congenital diseases was subsequently established in Pécs during the latter half of the study period, in 2009, which may explain the more current appearance and reporting of these rare syndromes.

The cleft team needed to modify the treatment algorithm for CLP in the majority ( $81 \%$ ) of the SCLP patients. One example of these alterations is the delay of the primary cleft repair operations. The main causes of the delay in palatoplasty for PRS patients were airway issues and feeding problems. In other patients, cardiorespiratory and urogenital interventions had priority over the cleft surgeries. Upper respiratory infections also caused a delay in the timing of the primary cleft operations in some cases [Figures 3 and 4].

The high rate $(37.5 \%)$ of the secondary operations such as speech improvement surgery and ancillary procedures such as placement of tympanostomy tubes for the SCLP patients is in accordance with the literature..$^{7,11,17-19]}$

The authors have noted velopharyngeal insufficiency and speech problems as more common conditions in SCLP patients, especially those patients with PRS. This explains the high rate of pharyngoplasties and tympanostomies in these patients. ${ }^{[7,17-19]}$ The author's findings support these observations. In some previous studies, however, no differences were found between the secondary operations for nonsyndromic patients and patients with PRS. ${ }^{[20]}$

\section{Conclusion}

The presence of a genetic syndrome noticeably altered the treatment algorithm of the PCT in the majority of children born with SCLP (81\%) compared to nonsyndromic CLP patients. The surgical treatment of the associated anomalies has priority over the timing of the reconstruction of the cleft lip and palate in a number of syndromic patients. Cleft palate only and velopharyngeal insufficiency were more common in the syndromic group. Secondary operations for clefts were needed in greater numbers in SCLP patients than in nonsyndromic patients. With improvements in pediatric care and better recognition of the milder phenotypes, the number of future SCLP patients is likely to increase. Syndromic patients 
will likely require further flexible modifications of the cleft treatment timing algorithm.

\section{Financial support and sponsorship}

Nil.

\section{Conflicts of interest}

Dr. George Kalman Sandor was associated as a section editor of this journal and this manuscript was subject to this journal's standard review procedures, with this peer review handled independently of this section editor and their research group.

\section{ReFERENCES}

1. Corcoran M, Karki S, Harila V, Luoto A, Ylikontiola L, Sándor GK, et al. Dental fear among adolescents with cleft. Int J Paediatr Dent 2021. p. 1-8.

2. Cohen MM Jr. Syndromes with cleft lip and cleft palate. Cleft Palate J 1978;15:306-28.

3. Venkatesh R. Syndromes and anomalies associated with cleft. Indian J Plast Surg 2009;42 Suppl: S51-5.

4. Saleem K, Zaib T, Sun W, Fu S. Assessment of candidate genes and genetic heterogeneity in human non syndromic orofacial clefts specifically non syndromic cleft lip with or without palate. Heliyon 2019;5:e03019.

5. Irfanulla Khan AN, Prashanth CS, Srinath N. Genetic etiology of cleft lip and cleft palate. AIMS Mol Sci 2020;7:328-48.

6. Online Mendelian Inheritance in Man, OMIM ${ }^{\circledR}$. McKusick-Nathans Institute of Genetic Medicine, Johns Hopkins University, Baltimore, MD. Available from: https://omim.org/. [Last Accessed on 2020 Sep 29].

7. Godbout A, Leclerc JE, Arteau-Gauthier I, Leclerc LD. Isolated versus Pierre Robin sequence cleft palates: Are they different? Cleft Palate Craniofac J 2014;51:406-11.

8. Cladis F, Kumar A, Grunwaldt L, Otteson T, Ford M, Losee JE. Pierre Robin sequence: A perioperative review. Anesth Analg 2014;119:400-12.

9. Karki S, Horváth J, Laitala ML, Vástyán A, Nagy Á, Sándor GK, et al.
Validating and assessing the oral health-related quality of life among Hungarian children with cleft lip and palate using Child-OIDP scale. Eur Arch Paediatr Dent 2021;22:57-65.

10. Corcoran M, Karki S, Harila V, Kyngäs H, Luoto A, Ylikontiola LP, et al. Oral health-related quality of life among young adults with cleft in northern Finland. Clin Exp Dent Res 2020;6:305-10.

11. Lehtonen V, Lithovius RH, Autio TJ, Sándor GK, Ylikontiola LP, Harila $\mathrm{V}$, et al. Middle ear findings and need for ventilation tubes among pediatric cleft lip and palate patients in northern Finland. J Craniomaxillofac Surg 2016;44:460-4.

12. Sárközi A, Wyszynski DF, Czeizel AE. Oral clefts with associated anomalies: Findings in the Hungarian Congenital Abnormality Registry. BMC Oral Health 2005;5:4.

13. Doray B, Badila-Timbolschi D, Schaefer E, Fattori D, Monga B, Dott B, et al. Epidemiology of orofacial clefts (1995-2006) in France (Congenital Malformations of Alsace Registry). Arch Pediatr 2012;19:1021-9.

14. Galil A, Carmi R, Goldstein E, Porter B, Bar Ziv J, Chemke J. Weissenbacher-Zweymuller syndrome: Long-term follow-up of growth and psychomotor development. Dev Med Child Neurol 1991;33:1104-9.

15. Bigatà X, Bielsa I, Artigas M, Azón A, Ribera M, Ferrándiz C. The ectrodactyly-ectodermal dysplasia-clefting syndrome (EEC): Report of five cases. Pediatr Dermatol 2003;20:113-8.

16. Malvankar DD, Sacchidanand S, Mallikarjun M. Ectrodactyly, ectodermal dysplasia, and cleft lip-palate (EEC) syndrome without clefting: A rare case report. Dermatol Online J 2012;18:5.

17. Hardwicke JT, Richards H, Cafferky L, Underwood I, Horst BT, Slator R. Outcomes of cleft palate repair in patients with Pierre Robin sequence: A matched case-control study. Plast Reconstr Surg 2016;137:927-35.

18. Kocaaslan FN, Sendur S, Koçak I, Çelebiler Ö. The comparison of Pierre Robin sequence and non-syndromic cleft palate. J Craniofac Surg 2020;31:226-9.

19. Gustafsson C, Vuola P, Leikola J, Heliövaara A. Pierre Robin sequence: Incidence of speech-correcting surgeries and fistula formation. Cleft Palate Craniofac J 2020;57:344-51.

20. Stransky C, Basta M, Solot C, Cohen M, Low DW, Larossa D, et al. Do patients with Pierre Robin sequence have worse outcomes after cleft palate surgery? Ann Plast Surg 2013;71:292-6. 